\title{
The Effects of Intelligence and Personality on Performance in Simulated Interrogation Scenarios
}

\author{
Robert Morgan $^{1} \cdot$ Laurence Alison $^{1} \cdot$ Marek Palace $^{2}$ (I) $\cdot$ Neil Shortland $^{3} \cdot$ Michael Humann $^{1}$
}

Accepted: 5 October 2020 / Published online: 30 October 2020

(c) The Author(s) 2020

\begin{abstract}
The paper explores the relationships between individual differences in intelligence and personality and the ability to extract critical information (and identify missing but required information) from a suspect's brief sheet (i.e. model formulation) and develop a suitable line of questioning (i.e. approach strategizing) in interrogation scenarios. We hypothesised that cognitive flexibility, emotion management, low need for closure and rapport would all be predictors of these abilities. Two hundred and seventy-four participants of different backgrounds were exposed to two interrogation scenarios to assess model formation and approach strategizing abilities, as well as intelligence and personality tests. Benchmarks for performance were measured against two experienced interrogators and two psychologists' calibrated performance. In terms of overall performance, only rapport and cognitive flexibility were significant positive predictors. Whereas only rapport was a positive predictor of approach strategizing, both rapport and cognitive flexibility were positive predictors of model formation. In conclusion, the data from the early stage of our project suggests that the examined factors should be carefully considered when training and selecting optimal interrogators. Though previous research has identified a number of individual differences in intelligence and personality that are important in demanding law-enforcement contexts, ours is the first to explore them with respect to effective interrogator performance.
\end{abstract}

Keywords Personality $\cdot$ Intelligence $\cdot$ Interrogation $\cdot$ Simulated scenarios

\section{Introduction}

Although interrogations are an integral part of the investigative process, little is known about the cognitive skills and traits that underpin effective performance in this domain. What is known, however, is that interrogations are cognitively and emotionally demanding for those who conduct them (Kleider-Offutt et al. 2016). Though previous research has identified a number of individual differences in intelligence and personality that are important in other, similarly demanding, law-enforcement contexts (Larmour et al. 2015), none has been investigated with respect to effective

Marek Palace

marekpalace@hotmail.com

1 School of Psychology, University of Liverpool, Liverpool, United Kingdom

2 School of Psychology, Liverpool John Moores University, Liverpool, United Kingdom

3 Center for Terrorism and Security Studies, University of Massachusetts Lowell, Lowell, United States of America interrogator performance (e.g. Alison et al. 2013b; Kleider et al. 2010). Defining such performance is itself a challenge, but the present study proposes that two important antecedents of interrogation performance are model formation and approach strategizing.

Model formation involves the examination of available case information to determine what is critically relevant and what is currently unknown but required. The more critical information that can be extracted from the brief, the stronger and more specific the model and, thus, the interrogator's understanding of the case. Knowledge of what information is missing is also beneficial, since this informs what followup questions will be asked of both the senior investigating officer and the suspect. Approach strategizing is the process of developing a line of questioning and predicting a suspect's response.

The expected outcome of this process is the identification of the key questions that will satisfy the interrogator's objectives. Furthermore, the interrogator will be, to one degree or another, prepared for how the suspect might respond and can therefore mentally rehearse how to address the suspect's 
comments (or lack thereof). Hence, approach strategizing is closely linked with the concept of anticipation which is, elsewhere, shown to allow individuals to anticipate future outcomes of actions and mentally planning responses to them (e.g. Skulimowski \& Kacprzyk 1997).

In terms of our understanding of interrogations, in the military domain, the large-scale revelations surrounding the use of 'enhanced' interrogation methods in Iraq and Afghanistan spurred a critical debate about the legality and, crucially, effectiveness or coercive methods for eliciting information (see Evans et al. 2017). Similarly, police interrogation methods have equally been questioned for "creating' false confessions and wrongful convictions (Redlich \& Meissner 2009). There are also stark cultural differenceswhereas American and Canadian interrogators were found to be similar to one another, and conformed to an accusatorial approach (in both deception detection and questioning techniques), the interviewers from Europe, Australia and New Zealand conformed more to an information-gathering approach (Miller et al. 2018). While US jail inmates endorsed interrogation strategies characterised by respect, dignity and commitment to the truth and were opposed to those involving false evidence and aggression (Cleary \& Bul 2018), specific offender-victim profiles were found to result in a greater likelihood of confession in sexual assault investigations (Beauregard et al. 2017).

These controversies have created a need for systematic empirical research to identify 'what works' in an interrogation situation (Senate Select Committee on Intelligence, 2014). Given this, in the past, researchers have used surveys, interviews, experimental research and observations to learn about techniques used within an interrogation that are effective at eliciting accurate information (Kelly et al. 2016). Such work has focused on the effectiveness of different question styles (accusatorial vs. information-gathering; see Meissner et al., 2014), with much work often focusing on whether a certain questioning tactic was used or to what extent (Kelly et al. 2016). Other work has focused (as have many other studies) on the central role of rapport and specifically the inter-personal dynamics that create good rapport and the positive effect of good rapport on intelligence yield and the use of counter-interrogation tactics (e.g. answering 'no comment', see Alison et al. 2013a, b, 2014a, b, 2017; Kelly et al. 2016; Meissner et al. 2015). However, there is almost no research at all on the role that individual differences in personality and cognitive factors play in the ability of an interrogator to prepare for, and respond during, an interrogation.

Given this, this research seeks to examine the cognitive correlates of model formation and approach strategizing in interrogation scenarios. Integrating previous findings of the effects of individual differences on specific law enforcement tasks with this novel approach to measuring interrogator performance serves two purposes. Firstly, it furthers academic understanding of the psychological dynamics the interrogation (rather than the dyadic process of 'interrogation') and, secondly, it may lead to new avenues for the training and development of interrogators. While there has been no prior work specifically in this area, based on a review of the literature on decision-making in other high-uncertainty areas (e.g. military and police operations; e.g. Alison et al. 2013a, b), the present research focusses on four measures of intelligence-fluid mental ability, cognitive flexibility, emotional understanding and emotion management-and two measures of personality-need for closure and trait emotional intelligence. We outline each of these factors in detail down below.

\section{Need for Closure}

Those with low need for closure (NFC) are more often 'adaptable, open-minded, less focused on certainty, and happy to expend longer periods of time before taking action' (Evans et al. 2017, p. 1194). High NFC individuals achieve closure through the processes of seizing and freezing. Such individuals seize 'early, closure-affording evidence' before they then freeze on the conclusion or judgement it suggests (Kruglanski et al. 2009, p. 151). Having achieved closure, these individuals tend to demonstrate behavioural patterns that ensure closure is not compromised, including lowered motivation to search for additional information and lowered sensitivity to alternative hypotheses (Roets \& Van Hiel 2007). Low NFC individuals may have an advantage when it comes to predicting a suspect's response to their questions, as research suggests that those with high NFC are less empathic towards others because of their rigid interpretation of the situation (Nelson et al. 2003). The cognitive adaptability associated with low NFC may, therefore, allow for flexibility in the conceptualisation of the situation, which, in turn, permits low need for closure individuals to empathise with the suspect's perspective (Meadows et al. 2017).

\section{Cognitive Flexibility}

Individuals with high cognitive flexibility (CF) have enhanced attentional control, information processing and plan formation capabilities. This enables them to adapt their cognitive system to changing contexts and demands (Varanda \& Fernandes 2017). CF has also been explored in relation to decision making and problem solving (LaureiroMartínez \& Brusoni 2018). Research suggests that those with high $\mathrm{CF}$ are more effective at these tasks because they engage two mechanisms-identifying and reflecting-to aid cognition. Initially, individuals identify the problem elements and their discrepancies, before subsequently reflecting on the relationships between elements to establish cause and 
effect (Raes et al. 2011). In essence, high CF individuals utilise a feedback loop to update their perspective and, thus, continually iterate and adapt to changing environments (Furr et al.2012). Considering these abilities and mechanisms, high CF should prove valuable to both model formation and approach strategizing. Firstly, high CF individuals should be able to make use of their heightened information processing skills-through identifying and reflecting-as well as their increased awareness of alternatives, to extract and request more information. Equally, compared with individuals with low $\mathrm{CF}$, those with high $\mathrm{CF}$ ought to be more effective at approach strategizing since the process relies substantially on both plan formation (to set the priority questions) and interpersonal communication skills (to anticipate a suspect's response).

\section{Emotional Intelligence}

The effect of emotional intelligence (EI) on general cognition is relatively unexplored, although there is some evidence to suggest that EI has a weak positive relationship with executive functioning. For example, small-to-medium effect sizes were reported when emotional understanding was correlated with working memory, attentional control and problem solving (Pardeller et al. 2017).

Given the cognitively and emotionally demanding nature of interrogations, high working memory capacity is essential, and thus, those with high trait EI may well be at a disadvantage for both model formation and approach strategizing. Interrogators with strong EI, on the other hand, may well outperform their less-able peers due to their capacity to integrate emotional information into their cognitive processes. Predicting a suspect's response, for instance, should be facilitated by emotional understanding, as the knowledge of the relationship between thoughts, feelings and emotions can be used to predict how a suspect will respond when confronted with a question. Equally, emotion regulation (or management) may prove advantageous, because the interrogator can choose whether (or not) to attend to emotional cues present in the environment. In doing so, the individual can generate questions based on these cues (such as asking if a suspect is under duress when they appear anxious or frightened), while also avoiding an overly sympathetic and thus emotionally inappropriate state.

\section{RBI}

Building on extensive research into suspect interviewing, the Rapport-Based Inventory (RBI) for investigative interviewers was developed to measure interviewers' rapport-based skill level based on motivational interviewing (MI) theory. MI is a person-centred, evidence-based clinical intervention originally developed to treat substance misuse. Investigative interviewers who use strategies consistent with the principles of MI have been found to engage suspects and obtain increased information yield in interview (Alison et al. 2013a, b; Surmon-Böhr et al. 2020). The RBI consists of vignettes based on real interviews with suspects, with each vignette followed by questions that prompt the respondent to select or write a response that are then scored against MI standards. Two studies were recently conducted to test the internal reliability and external validity of the scale (SurmonBöhr, Alison \& Alison, 2020). In the first study, the RBI was administered to a large sample of police interviewers $(n=140)$ and students $(n=85)$. The findings indicated good inter-rater reliability of scoring, and the scale was found to have good internal consistency. In the second study, the RBI was administered to a sample of police interviewers taking part in a National Counterterrorism training course to assess whether RBI scores were associated with interviewer performance during mock interviews $(n=60)$. The RBI displayed good concurrent validity with a behavioural sample of interviewer performance during mock interviews, measured using the ORBIT coding framework.

\section{Present Research}

Selecting people who have the right knowledge, skills and abilities is essential for any role in any organisation, and increasing research is focussing on identifying personality and cognitive traits that may predict success (e.g. see Wiersma \& Kappe, 2016). The present research seeks to support this objective in a unique and underexplored domain by providing initial insight into the intelligence and personality aspects that are likely to determine how effectively interrogators are able to process case-specific details and formulate lines of inquiry. The inclusion of specific correlates in the following exploratory analysis was based upon their previously established links to the investigative process (e.g. Alison et al. 2013b), as well as their predicted (dis) advantages for the model formation and approach strategizing processes. Based on the literature discussed above, the following hypotheses were generated:

Hypothesis 1 Those with high cognitive flexibility would exhibit higher scores for: overall performance, model formation; and approach strategizing.

Hypothesis 2 Those with low need for closure would show better scores for overall performance, approach strategizing and model formation.

Hypothesis 3 Those with high emotional management would exhibit higher scores for overall performance, model formation and approach strategizing. 
Hypothesis 4 Those with high rapport scores would perform better in overall performance, model formation and approach strategizing.

\section{Method}

\section{Participants}

Two hundred and seventy-four participants of different backgrounds (81 male and 193 female) were recruited via opportunity sampling to complete an online questionnaire shared on Facebook and the university participant recruitment scheme. Their age ranged from 18 to $69(M=28.2$, $S E=0.83$ ). There were no restrictions on who could take part in the research. We used the following measures:

- The Revised Need for Closure Scale (NFCS(R) - Roets \& Van Hiel 2007).

- Cognitive flexibility: Dennis and Vander Wal's (2010) Cognitive Flexibility Inventory (CFI), which is specifically designed for the measurement of cognitive flexibility in research contexts.

- Emotion management: The Situational Test of Emotion Management-Brief (STEM-B), which is a much shorter assessment of emotion management than the original version; however, it preserves its full-version reliability ( $\alpha=.84)$ (Allen et al. 2015).

- The Rapport Base Interviewing (RBI), which is a measure used to test ability to demonstrate key motivational interviewing skills (Surmon-Böhr et al.2020).

Building on the related research on the level of suspicion and counter-interrogation tactics (Granhag et al. 2009), we presented participants with two different interrogation scenarios. Both scenarios featured an imminent and unspecified threat of a terrorist attack in an unspecified location, but they differed in involving directly and indirectly implicated suspects, ${ }^{1}$ the implication being the presented suspect playing either the main or peripheral role in the terror plot. Participants were tasked with asking questions about them, using both multiple choice and open-ended options. The scenarios, in which participants were asked to act as investigators reporting to their Senior Investigating Officer (SIO), were measured against the different questionnaires to test the level of ability they would have for approach strategizing and model formation. Drawing upon best practices used within law enforcement, participants' responses were measured against responses given by four experts:

\footnotetext{
1 The contents might be shared by the authors, subject to institutional ethics clearance.
}

two interrogation-trained psychologists and two counterterrorism detectives. The psychologists and detectives were in agreement with the proposed standard (inter-rater reliability Kappa $=0.8$ ). A 5-min timer was also set up for the scenarios.

\section{Procedure}

The questionnaires and scenarios for the study were presented using the online-based survey software Qualtrics. Firstly, participants were shown an information sheet with an overview of the study and a consent form. They also indicated their age, gender and interrogation experience. Participants then completed the emotional management 18-item questionnaire. This was followed by an example of the scenario they were going to be faced with and example answers. Since participants were not professionals, this was designed to help them think of more answers, as well as prepare them for the questions they would be asked.

The scenario explained the brief and asked four questions: (1) what critical information can be extracted from the brief; (2) what further information, if any, do I need from the SIO; (3) what are the priority question(s) that must be put to the suspect; and (4) what are the suspects' likely defences to these questions. Participants' responses were time-limited-they had $5 \mathrm{~min}$ to answer the four questions, which were meant to apply slight, but fairly realistic, pressure. The questionnaire included multiple choice questions to understand the attention paid to the study and a participant debrief sheet which explained the aims of the study, also providing helplines for the sensitive topics mentioned.

\section{Analysis}

Responses to the 16 questions were extracted from the full dataset, generating a relevance score according to the number of pieces of information that matched the standard. A response was considered to match the expert standard when it specifically used a keyword or was synonymous for a theme. After initial grouping of participants based on their performance and checking the internal consistency of the four individual measures, scores between low and high performers were compared and linear regression was carried out.

\section{Results}

In order to separate high from low performers and to facilitate the accessibility and understanding of our findings to trained interrogators, each of the three performance indicators were split into quartiles. High performers were 75th 
Table 1 Descriptive overview of the four variables

\begin{tabular}{llll}
\hline Variable & Low performer & High performer & Sig \\
\hline RBI & $M=19.85, S E=0.69$ & $M=24.11, S E=0.52$ & $t(146.78)=-4.9, p<.001$ \\
CFI & $M=100.14, S E=1.43$ & $M=105.94, S E=1.4$ & $t(157.91)=-2.9, p=.004$ \\
EM & $M=0.61, S E=0.01$ & $M=0.60, S E=0.01$ & \\
NFC & $M=3.66, S E=0.11$ & $M=3.68, S E=0.11$ & \\
\hline
\end{tabular}

percentile to the maximum score, and low performers were the minimum score to the 25 th percentile.

\section{Preliminary Analysis}

The $\alpha$-acceptability threshold was set at .6 (Pallant 2020). Consequently, CFI $(\alpha=.89)$, NFC ( $\alpha=.74)$, EM $(\alpha=.64)$ and rapport $(\alpha=.66)$ were all internally consistent measures (Table 1). Therefore, all measures were analysed against overall performance, model formation and approach strategizing.

\section{Overall Performance}

After comparing high and low scores it was found that rapport showed a significant difference between high $(M=24.11, S E=0.52)$ and low $(M=19.85, S E=0.69)$ performers $(t(146.78)=-4.9, p<.001)$. CF also showed a significant difference between high $(M=105.94, S E=1.4)$ and low $(M=100.14, S E=1.43)$ performers $(t(157.91)=-2.9$, $p=.004)$. However, EM showed no significant difference between high $(M=0.60, S E=0.01)$ and low $(M=0.61$, $S E=0.01)$ scores, neither did NFC $(M=3.68, S E=0.11$; $M=3.66, S E=0.11$ ).

Linear regression analysis was run to predict overall performance scores from CF, NFC, EM and rapport. Overall, these variables significantly predicted overall performance $(F(4,273)=10.16, p<.001)$, with an $R^{2}$ of .13 . However, when overall performance was predicted, it was found that rapport $(B=.32, p<.001)$ and cognitive flexibility total $(B=.14, p=.03$ ) were significant predictors. Need for closure $(B=.02, p=.72)$ and emotional management ( $B=-.07, p=.22$ ) were not significant predictors. This shows that overall performance will increase with increased scores on the RBI and slightly on the CFI and NFC-R.

\section{Approach Strategizing}

There was a significant difference between the high $(M=23.35, S E=0.49)$ and low scorers $(M=20.57$, $S E=0.52)$ within approach strategizing for rapport $(t(218.56)=-3.9, p<.001)$. There were no significant differences between the high and low scores for $\mathrm{CF}$ $(M=103.86, S E=1.36 ; M=102.58, S E=1.24), \mathrm{EM}$ $(M=0.59, S E=0.01 ; M=0.6, S E=0.01)$ and $\mathrm{NFC}$
Table 2 Approach strategizing

\begin{tabular}{lrl}
\hline Predictor & \multicolumn{1}{c}{$\beta$} & \multicolumn{1}{c}{$p$} \\
\hline RBI & .24 & .001 \\
CFI & .06 & .36 \\
EM & -.04 & .5 \\
NFC & .56 & .58 \\
\hline
\end{tabular}

Table 3 Model formation

\begin{tabular}{lcc}
\hline Predictor & $\beta$ & $p$ \\
\hline RBI & .29 & .001 \\
CFI & .16 & .001 \\
EM & -.08 & .20 \\
NFC & .004 & .95 \\
\hline
\end{tabular}

$(M=3.82, S E=0.11 ; M=3.74, S E=0.08)$. Linear regression analysis showed that $\mathrm{CF}, \mathrm{NFC}, \mathrm{EM}$ and rapport significantly predicted approach strategizing $(F(4,273)=4.65$, $p=.001)$, with an $R^{2}$ of .07 . Individually, the only significant predictor of approach strategizing was rapport $(B=.24$, $p<.001)$. On the other hand, CF $(B=.06, p=.36)$, NFC $(B=.56, p=.58)$ and $\mathrm{EM}(B=-.04, p=.5)$ were not significant predictors of approach strategizing (Table 2).

\section{Model Formation}

A significant difference was found between the high $(M=23.99, S E=0.45)$ and low scorers $(M=20.22$, $S E=0.63)$ within model formation for rapport $(t(159.61)=-4.86, p<.001)$. CF also showed a significant difference between the high $(M=106.02, S E=1.3)$ and low $(M=98.8, S E=1.46)$ scorers $(t(173.34)=-3.68$, $p<.001)$. However, no significant differences were found for the EM high $(M=0.60, S E=0.11)$ and low $(M=0.61$, $S E=0.13)$, nor for NFC high $(M=3.7, S E=0.1)$ and low $(M=3.74, S E=0.11)$ scores. Linear regression analysis showed that $\mathrm{CF}, \mathrm{NFC}$, EM and rapport significantly predicted model formation $(F(4,273)=9.61, p<.001)$, with an $R^{2}$ of .13 . Individually, rapport $(B=.29, p<.001)$ and $\mathrm{CF}(B=.16, p<.01)$ were significant predictors of model formation. NFC $(B=.004, p=.95)$ and $\operatorname{EM}(B=-.08$, $p=.2$ ) were non-significant predictors of model formation (Table 3). 


\section{Discussion}

The present study explored the effects of intelligence and personality on model formation and approach strategizing, which are argued to underpin effective interrogator performance. Focusing on the findings relevant to our hypotheses, a cautious approach of avoiding unwarranted speculation and overinterpretation was adopted. The results partially support Hypothesis 1 (i.e. higher cognitive flexibility being positively correlated with overall performance and model formation) and fully support Hypothesis 4 (i.e. higher rapport being positively correlated with overall performance, model formation and approach strategizing). This is in line with research showing a positive correlation between intelligence and cognitive flexibility (Colzato et al. 2006; Gunduz 2013; Zmigrod et al. 2019). In terms of overall performance, the strongest approach strategizing abilities were observed in those participants with the highest rapport scores and in those with highest cognitive flexibility scores. This, in turn, is consistent with research on rapport-based interviewing (Alison et al., 2013a, b; Alison et al. 2014) and on cognitive flexibility (Koesten et al. 2009; Furr et al. 2012; Raes et al. 2011; Varanda \& Fernande 2017; Laureiro-Martínez \& Brusoni, 2018). Thus, higher cognitive flexibility appears to facilitate a larger repertoire of strategies to fit the situation, allowing a greater number of possible suspect responses (Koesten et al. 2009).

Need for closure, however, did not turn out to be a significant predictor. Considering the current literature, the null effects may be a consequence of the present study's definitions of model formation and approach strategizing. Given the potentially competing benefits of high and low need for closure, a high score in one aspect of model formation or approach strategizing could be cancelled out by a low score in the other.

The null effects of emotion management may be the result of a lack of sufficient emotional cues in the case brief. When there are few cues available, or the available cues do not contain enough information, inferring affective states and their corresponding behaviours becomes an unmanageable task, even for those with a substantial capacity for social information processing (Westerman \& Tamborin 2008). Specifically, without indicators of past behaviour, it may not have been possible for participants to make accurate predictions about future behaviours (i.e. how the suspect would respond to questioning) (Lee \& Harris 2013). Such null effects of emotion management can also clarify why the effect sizes of previously reported correlations between emotional understanding, working memory, attentional control and problem solving were only small to medium, rather than large (Pardeller et al.
2017). This is also consistent with the absence of established link between trait emotional intelligence and either elaborative thinking or the quantity of ideas produced in response to a stimulus (Sánchez-Ruiz et al. 2011). Consequently, individuals with high trait emotional intelligence may have no advantage over their low trait emotional intelligence peers (or vice versa) when it comes to overall performance, model formation and approach strategizing.

The current results provide implications for the academic understanding of the cognitive underpinnings of the process of interrogation and can inform issues of selection, training and development of interrogators. If, as argued, model formation and approach strategizing are the central cognitive processes involved in interrogation, these results represent the initial insight into the intelligence and personality correlates that underpin important elements of effective interrogator performance. Further research can clarify if these processes accurately reflect the operational practices of interrogators or whether there are additional aspects that have not yet been considered. Subsequent studies can also explore how these cognitive skills relate to the interpersonal behaviours and traits that are essential for rapport building and its associated effects on counter-interrogation strategies and intelligence yield (Alison et al., 2013a,b; 2014).

The individual difference measures used by the present research are easily deployed and, with further improvement, could potentially form the basis of an initial screening test for those who wish to become interrogators. This, in turn, will facilitate a more mature understanding of the effect of intelligence and personality on interrogator performance, which will support not only applicant screening but also the introduction of targeted exercises aimed at improving other related and essential interrogation skills (e.g. divergent thinking).

Although there is considerable value in these findings, the present study is not without shortcomings. In both the univariate and multivariate regression models, the majority of variance was unexplained. This signifies that there are factors affecting model formation and approach strategizing performance that the present study has not identified. It is possible that some of this variance can be explained by the missing intelligence measures (fluid mental ability and emotional understanding), and future research should look to explore this.

The validity of the scenarios-as accurate representations of interrogations-is limited, not least because they are absent of any interpersonal contact. Unlike a live interrogation, participants were not required to adapt to the suspect's behaviour or responses, nor were they subject to environmental stressors, such as time pressure, realistic stakes or risk to life. To address this issue, forthcoming research should look to develop a test protocol that can be applied in a more immersive training environment, where dynamism and 
face-to-face communication are facilitated and where other types of imminent threats are presented. Additionally, the uneven split between male and female participants suggests caution with data interpretation, which will be addressed in the next stage of our project. The next stage will go beyond emotional management and include a broader measure of ability-based emotional intelligence (Mayer et al. 2003) so as to cover all four branches of emotional intelligence.

The current early project results suggest that certain aspects of intelligence and personality-namely, rapport and cognitive flexibility-are positive predictors of overall interview performance. More specifically, whereas approach strategizing can be predicted by higher rapport, model formation can be predicted by both higher rapport and higher cognitive flexibility. It is suggested that individuals who exhibit these skills and traits also possess, amongst their other attributes, increased levels of emotional intelligence and ideational fluidity. These findings help increase our understanding of what defines an effective interrogator and, with the aid of further research, may contribute to better interrogation practice.

Open Access This article is licensed under a Creative Commons Attribution 4.0 International License, which permits use, sharing, adaptation, distribution and reproduction in any medium or format, as long as you give appropriate credit to the original author(s) and the source, provide a link to the Creative Commons licence, and indicate if changes were made. The images or other third party material in this article are included in the article's Creative Commons licence, unless indicated otherwise in a credit line to the material. If material is not included in the article's Creative Commons licence and your intended use is not permitted by statutory regulation or exceeds the permitted use, you will need to obtain permission directly from the copyright holder. To view a copy of this licence, visit http://creativecommons.org/licenses/by/4.0/.

\section{References}

Alison L \& Alison E (2017) Revenge versus rapport: Interrogation, terrorism, and torture. American Psychologist: 72(3): 266

Alison LJ, Alison E, Noone G, Elntib S, Christiansen P (2013) Why tough tactics fail and rapport gets results: Observing RapportBased Interpersonal Techniques (ORBIT) to generate useful information from terrorists. Psychology, Public Policy, and Law 19(4):411-433

Alison L, Doran B, Long ML, Power N, Humphrey A (2013) The effects of subjective time pressure and individual differences on hypotheses generation and action prioritization in police investigations. J Exp Psychol: Applied 19(1):83-93

Alison L, Alison E, Noone G, Elntib S, Waring S, Christiansen P (2014) The efficacy of rapport-based techniques for minimizing counter-interrogation tactics amongst a field sample of terrorists. Psychology, Public Policy, and Law 20(4):421-430

Alison L, Alison E, Noone G, Elntib S, Waring S \& Christiansen P (2014) Whatever you say, say nothing: Individual differences in counter interrogation tactics amongst a field sample of right wing, $A Q$ inspired and paramilitary terrorists. Personality and Individual Differences 68:170-175
Allen V, Rahman N, Weissman A, MacCann C, Lewis C, Roberts RD (2015) The Situational Test of Emotional Management-Brief (STEM-B): development and validation using item response theory and latent class analysis. Personality Individ Differ 81:195-200

Beauregard E, Busina I, Healey J (2017) Confessions of sex offenders: extracting offender and victim profiles for investigative interviewing. J Crim Psychol 7(1):13-28

Cleary HM, Bull R (2018) Jail inmates' perspectives on police interrogation. Psychology, Crime \& Law 25(2):157-170

Colzato LS, Van Wouwe NC, Lavender TJ, Hommel B (2006) Intelligence and cognitive flexibility: fluid intelligence correlates with feature "unbinding" across perception and action. Psychon Bull Rev 13(6):1043-1048

Dennis JP, Vander Wal JS (2010) The cognitive flexibility inventory: instrument development and estimates of reliability and validity. Cognitive Therapy and Research 34(3):241-253

Evans NJ, Rae B, Bushmakin M, Rubin M, Brown SD (2017) Need for closure is associated with urgency in perceptual decisionmaking. Memory \& Cognition 45(7):1193-1205

Furr NR, Cavarretta F, Garg S (2012) Who changes course? The role of domain knowledge and novel framing in making technology changes. Strategic Entrepreneurship Journal 6(3):236-256

Granhag PA, Clemens F, Strömwall LA (2009) The usual and the unusual suspects: level of suspicion and counter-interrogation tactics. JIP-OP 6(2):129-137

Gunduz B (2013) Emotional intelligence, cognitive flexibility and psychological symptoms in pre-service teachers. Educational research and reviews 8(13):1048-1056

Kelly CE, Miller JC, Redlich AD (2016) The dynamic nature of interrogation. Law Hum Behav 40(3):295-309

Kleider HM, Parrott DJ, King TZ (2010) Shooting behaviour: how working memory and negative emotionality influence police officer shoot decisions. Applied Cognitive Psychology 24(5):707-717

Kleider-Offutt HM, Clevinger AM, Bond AD (2016) Working memory and cognitive load in the legal system: influences on police shooting decisions, interrogation and jury decisions. J Appl Res Mem Cogn 5(4):426-433

Koesten J, Schrodt P, Ford DJ (2009) Cognitive flexibility as a mediator of family communication environments and young adults' well-being. Health Communication 24(1):82-94

Kruglanski AW, Dechesne M, Orehek E, Pierro A (2009) Three decades of lay epistemics: the why, how, and who of knowledge formation. European Review of Social Psychology 20(1):146-191

Larmour SR, Bergstrøm H, Gillen CT, Forth AE (2015) Behind the confession: relating false confession, interrogative compliance, personality traits, and psychopathy. J Police Crim Psychol 30(2):94-102

Laureiro-Martínez D, Brusoni S (2018) Cognitive flexibility and adaptive decision-making: evidence from a laboratory study of expert decision makers. Strateg Manag J 39(4):1031-1058

Lee V, Harris L (2013) How social cognition can inform social decision making. Frontiers in Neuroscience 7:259

Meissner CA, Kelly CE, Woestehoff SA (2015) Improving the effectiveness of suspect interrogations. Annual Review of Law and Social Science 11:211-233

Meissner CA, Redlich AD, Michael SW, Evans JR, Camilletti CR, Bhatt S \& Brandon S (2014) Accusatorial and information-gathering interrogation methods and their effects on true and false confessions: A meta-analytic review. Journal of Experimental Criminology: 10(4): 459-486.

Mayer, J.D., Salovey, P., Caruso, D.R., \& Sitarenios, G. (2003). Measuring emotional intelligence with the MSCEIT V2. 0. Emotion, 3(1), 97-105. 
Meadows A, Higgs S, Burke SE, Dovidio JF, van Ryn M, Phelan SM (2017) Social dominance orientation, dispositional empathy, and need for cognitive closure moderate the impact of empathy-skills training, but not patient contact, on medical students' negative attitudes toward higher-weight patients. Frontiers in Psychology 8:504

Miller JC, Redlich AD, Kelly CE (2018) Accusatorial and informationgathering interview and interrogation methods: a multi-country comparison. Psychology, Crime \& Law 24(9):935-956

Nelson DW, Klein CT, Irvin JE (2003) Motivational antecedents of empathy: inhibiting effects of fatigue. Basic Appl Soc Psychol 25(1):37-50

Pallant, J. (2020). SPSS survival manual: a step by step guide to data analysis using IBM SPSS. Routledge.

Pardeller S, Frajo-Apor B, Kemmler G, Hofer A (2017) Emotional intelligence and cognitive abilities-associations and sex differences. Psychology, health \& medicine 22(8):1001-1010

Raes AM, Heijltjes MG, Glunk U, Roe RA (2011) The interface of the top management team and middle managers: a process model. Acad Manag Rev 36(1):102-126

Redlich AD \& Meissner CA (2009) Techniques and controversies in the interrogation of suspects. Psychological science in the courtroom, 124-148. Available at: https://www.researchgate.net/profile/Allis on_Redlich/publication/312975455_Interview_and_interrogat ion_methods_and_their_effects_on_true_and_false_confession s/links/5a396b2b0f7e9baa501796e8/Interviewand-interrogat ion-methods-and-their-effects-on-true-and-false-confessions.pdf

Roets A, Van Hiel A (2007) Separating ability from need: clarifying the dimensional structure of the need for closure scale. Pers Soc Psychol Bull 33(2):266-280

Sánchez-Ruiz MJ, Hernández-Torrano D, Pérez-González JC, Batey M, Petrides KV (2011) The relationship between trait emotional intelligence and creativity across subject domains. Motivation and Emotion 35(4):461-473

Alison, L., Alison, E., Noone, G., Elntib, S., Waring, S., \& Christiansen, P. (2014). The efficacy of rapport-based techniques for minimizing counter-interrogation tactics amongst a field sample of terrorists. Psychology, public policy, and law, 20(4), 421

Skulimowski, A., \& Kacprzyk, J. (1997). Knowledge, information and creativity support systems: Recent trends, advances and solutions. In KICSS2013-8th International Conference on Knowledge, Information, and Creativity Support Systems (Vol. 364).

United States. Congress. Senate. Select Committee on Intelligence, \& Feinstein D (2014) Report of the Senate Select Committee on Intelligence Committee Study of the Central Intelligence Agency's Detention and Interrogation Program, Together with Foreword by Chairman Feinstein and Additional and Minority Views. US Government Printing Office.

Varanda, C.D.A. \& Fernandes, F.D.M. (2017). Cognitive flexibility training intervention among children with autism: a longitudinal study. Psicologia: Reflexão e Crítica, 30.

Westerman, D.K. \& Tamborini, R. (2008). Uncertainty reduction over time in initial stranger interactions: a social information processing theory approach. In Annual meeting of the International Communication Association, Montreal, QC, Canada.

Wiersma, U.J. (2016, December). The four stages of the employment interview. In Evidence-based HRM: a Global Forum for Empirical Scholarship. Emerald Group Publishing Limited.

Zmigrod L, Zmigrod S, Rentfrow PJ, Robbins TW (2019) The psychological roots of intellectual humility: the role of intelligence and cognitive flexibility. Personality Individ Differ 141:200-208 